\title{
A prospective study of daclatasvir and sofosbuvir in chronic HCV-infected kidney transplant recipients
}

\author{
Michael Duerr ${ }^{1 *}$ (D) Eva V. Schrezenmeier ${ }^{1}$, Lukas J. Lehner ${ }^{1}$, Léon Bergfeld ${ }^{1}$, Petra Glander ${ }^{1}$, \\ Stephan R. Marticorena Garcia², Christian E. Althoff², Ingolf Sack², Susanne Brakemeier ${ }^{1}$, Kai-Uwe Eckardt ${ }^{1}$, \\ Klemens Budde ${ }^{1}$ and Fabian Halleck
}

\begin{abstract}
Background: Only a few prospective trials exist regarding the use of novel direct-acting antiviral agents (DAAs) in kidney transplant recipients (KTR) with chronic hepatitis $\mathrm{C}$ virus (HCV) infection.

Methods: This prospective single-center trial evaluated treatment with daclatasvir (DCV) and sofosbuvir (SOF) over 12 weeks in 16 adult chronic HCV infected KTR and eGFR $>30 \mathrm{ml} / \mathrm{min} / 1.73 \mathrm{~m}^{2}$. Primary endpoint was sustained virological response 12 weeks after end of therapy (SVR12). Beside baseline liver biopsy, hepatic function and glucose metabolism were regularly assessed.

Results: Four of 16 study patients had previously failed interferon-based HCV treatment. Liver biopsy showed mostly moderate fibrosis score before therapy with DCV/SOF was initiated at a median of 10.3 years after transplantation. In total, 15 of 16 KTR achieved SVR12. One patient showed early viral relapse because of resistanceassociated variants (RAVs) in the HCV NS5A region. Rescue treatment with SOF/velpatasvir/voxilaprevir resulted in SVR12. DAAs treatment led to significant improvement of liver metabolism and glucose tolerance accompanied with no therapy-associated major adverse events and excellent tolerability.
\end{abstract}

Conclusions: Our study demonstrates safety, efficacy and functional benefit of DCV/SOF treatment in KTR with chronic HCV infection. We provide data on rescue strategies for treatment failures due to present RAVs and amelioration of hepatic function and glucose tolerance.

Trial registration: Registry name: European Clinical Trials Register; Trial registry number (Eudra-CT): 2014-00455132, Registration date: Aug 28th 2015.

Keywords: Kidney transplantation, HCV infection, Direct-acting antivirals, Daclatasvir, Sofosbuvir

\section{Background}

Chronic hepatitis C Virus (HCV) infection represents an additional disease burden for affected kidney transplant recipients (KTR) with a negative impact on patient and graft survival [1-3]. There are a variety of long-term consequences of chronic $\mathrm{HCV}$ infection such as liver function impairment, consecutive liver fibrosis and cirrhosis and hepatocellular carcinoma. In addition, $\mathrm{HCV}$-associated extra-hepatic manifestations can lead to

\footnotetext{
* Correspondence: michael.duerr@charite.de

${ }^{1}$ Department of Nephrology and Medical Intensive Care, Charité

Universitätsmedizin Berlin, Augustenburger Platz, 13353 Berlin, Germany

Full list of author information is available at the end of the article
}

premature renal allograft loss, e.g. due to recurrence of $\mathrm{HCV}$-associated membranoproliferative glomerulonephritis, post-transplant diabetes, a higher incidence of rejections and post-transplant malignancies [4-7]. Before the approval of the novel direct-acting antivirals (DAAs) pegylated interferon (pegIFN) and ribavirin (RBV) were used for treatment of chronic HCV infection. However, these drugs had low efficacy with frequent treatment failures, persistent $\mathrm{HCV}$ replication or viral relapse. In addition, multiple severe side effects caused a high rate of drug discontinuations. In particular, the immunomodulatory properties of pegIFN are associated with a higher risk of acute rejection and increased rates of graft loss

(c) The Author(s). 2019 Open Access This article is distributed under the terms of the Creative Commons Attribution 4.0 International License (http://creativecommons.org/licenses/by/4.0/), which permits unrestricted use, distribution, and 
$[8,9]$. Thus, pegIFN was not considered suitable for KTR while RBV alone does not result in a sustained HCV clearance.

With the development of the novel DAAs, treatment efficacy improved and drug-related side effects dramatically decreased in HCV-positive, non-organ-transplanted patients $[10,11]$. Daclatasvir (DCV) inhibits HCV RNA replication by specific inhibition of the viral NS5A protein. It was approved (2014 by EMA, 2015 by FDA) and is currently recommended for treatment of chronic $\mathrm{HCV}$ infection of genotypes 1-6 in combination with sofosbuvir (SOF), an inhibitor of the viral NS5B protein [12]. Both, NS5A and NS5B, are critical for viral transcription and translation [13].

The novel IFN-free, pan-genotypic combination regimen with DCV/SOF demonstrated robust and permanent $\mathrm{HCV}$ clearance also in advanced liver disease or HIV co-infected patients [14-17]. In KTR different SOF-based combination therapies already have been reported mostly in retrospective case series to cure chronic HCV infections in KTR [18-22]. However, prospective data on treatment with DCV/SOF in KTR with chronic $\mathrm{HCV}$ are limited.

Here we report the results of a prospective open-labeled trial to evaluate the efficacy and safety of a fixed dose 12-weeks regimen of DCV/SOF in HCV-infected KTR. Besides safety and efficacy, changes in hepatic and extra-hepatic parameters, glucose tolerance and possible drug-drug interactions are analyzed in detail.

\section{Methods}

\section{Study design and treatment}

In 2016 a prospective phase II, single-center, open-label trial (Eudra-CT number: 2014-004551-32) was started at our center. In total, $16 \mathrm{KTR}$ with chronic HCV infection received a 12-weeks course of DCV $60 \mathrm{mg}$ and SOF $400 \mathrm{mg}$ orally once daily given, followed by an additional 24-week observational follow-up period. Potential trial participants agreed to participate in the study by providing written informed consent after approval by German health authorities and an independent Ethic committee (15/0446EK15; $4,040,892)$. The study was conducted according the Declaration of Helsinki, the International Conference on Harmonization and Good Clinical Practice guidelines.

\section{Inclusion criteria}

We offered treatment to all adult KTR (age $>18$ years) of our outpatient clinic with chronic HCV infection and stable graft function for more than 12 months, defined as eGFR $>30 \mathrm{ml} / \mathrm{min} / 1.73 \mathrm{~m}^{2}$ using the CKD-EPI formula [23]. KTR were either treatment naïve or had previously failed treatment with any former regimen (without the use of novel DAAs). Chronic HCV infection was defined by > 3 months of positivity for anti-HCV antibody and $\mathrm{HCV}$ RNA viral load.

\section{Exclusion criteria}

KTR with any contraindications DCV/SOF, evidence for chronic liver disease other than $\mathrm{HCV}$ and KTR with Child-Pugh Class B or C (Score >6) were excluded from the study. Further exclusion criteria were: severe cardiac disease, malignancies in the last 5 years, any blood transfusions within 4 weeks, recent (within 6 months) drug or alcohol abuse (defined by [24]), coinfection with HIV or $\mathrm{HBV}$, severe rejection ( $\geq$ Banff II) or recurrent acute or chronic rejection within 6 months, neutrophils $\leq 1500 / \mathrm{mL}$, platelets $\leq 75.000 / \mathrm{mL}$, ALT $>5 \mathrm{x}$ upper limit of normal (ULN), direct bilirubin $>3 x \mathrm{xLN}$, Albumin $<3.0 \mathrm{~g} / \mathrm{dL}$.

\section{Efficacy endpoints}

The primary outcome was sustained virological response at week 12 after end of treatment (SVR12). SVR was defined as undetectable HCV RNA in a study participant with previously quantifiable or detectable HCV RNA.

Secondary efficacy outcomes were the proportion of renal transplant patients with SVR at week 4 (SVR4) and at week 24 (SVR24) after the end of treatment. Viral relapse was defined as confirmed quantifiable or detectable HCV RNA in a study participant with previously HCV RNA unquantifiable or undetectable by nucleic acid testing (NAT) after the end of treatment. In case of viral relapse, combined therapy with DCV $(60 \mathrm{mg} / \mathrm{d})$ and SOF $(400 \mathrm{mg} / \mathrm{d})$ was extended until week 24. If HCV RNA was still detectable after that extended period, therapy was stopped. Viral breakthrough was defined as confirmed increase in viral load $\geq 1 \log$ value from nadir or any confirmed HCV RNA beyond week 8 . In those KTR therapy with treatment was also stopped. At each visit time point HCV-RNA and clinical data were determined to follow closely the response to therapy (see Fig. 1).

\section{Safety}

We prospectively evaluated safety of treatment regimen at each visit in context of adverse events (AEs), serious AEs (SAEs), suspected unexpected severe adverse reaction (SUSAR) and drug discontinuations. Patient and graft survival including biopsy proven rejections (BPAR) according to BANFF scores [25] were documented. Events of particular interest as infections, clinically significant changes in vital signs or laboratory parameters including new-onset or changes of proteinuria and changes of eGFR at each study visit were captured. In general, participants were encouraged to report any side effects or adverse events at each trial visit.

\section{Assessment of glucose metabolism}

Consecutive oral glucose tolerance tests (OGTTs) were performed at BL, EOT and SVR12. 2-h plasma glucose concentrations, the preferred WHO diagnostic criteria for KTR, were the primary outcome for diagnosis of 


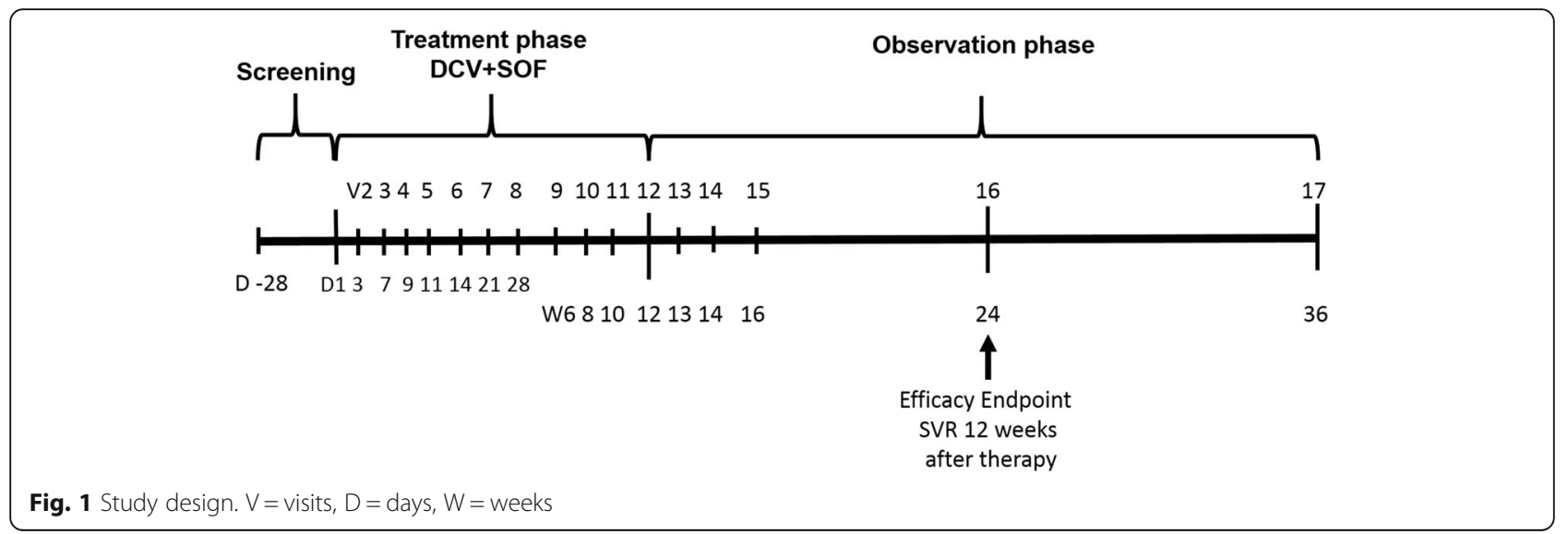

post-transplantat diabetes mellitus (PTDM) or impaired glucose tolerance (IGT) [26]. In addition in homeostatic model assessment indexes were assessed to identify insulin resistance and $\beta$-cell function (HOMA2-IR/-B) [27].

\section{Calcineurin inhibitor assessment}

Metabolism rate of tacrolimus (TAC) or ciclosporin A (CyA) treated patients were determined at predefined study visits (Screening, baseline, week (w) 1, 2, 4, 6, 8, 10, EOT, SVR4, -12 and -24 ) by dividing the drug blood trough concentration $(\mathrm{C})$ to the daily TAC or CyA dose (D) respectively.

$$
\begin{aligned}
& \mathrm{C} / \mathrm{D} \text { ratio }(\mathrm{ng} / \mathrm{ml} \times 1 / \mathrm{mg}) \\
& =\frac{\text { blood }(\text { CNI }) \text { trough level }\left(\frac{n g}{m l}\right)}{\text { daily CNI dose }(m g)}
\end{aligned}
$$

\section{Staging of liver disease}

Percutaneous intercostal ultrasound guided liver biopsies were performed (Acuson-X700, Siemens Erlangen, Germany) with at least three samples of the right lobe using a 18G Quick-Core Biopsy Needle (William Cook Europe, Bjaeverskov, Denmark) and a 17ga Co-Axial introducer Needle (Argon Medical Devices, Athens, USA). Biopsy samples with a minimum length of $2.0 \mathrm{~cm}$ were obtained and directly conserved in $4 \%$ Formalin. Because of increased risk of bleeding due to dual thrombocyte anti-coagulation at time of biopsy one patient was biopsied by sheath-mediated (8F) transjugular liver biopsy set (Liver Access and Biopys Needle Set, LABS-200-J, 19G; William Cook Europe). No complications according to Society of Interventional Radiology guidelines were detected in all patients [28].

Histopathological findings were reported and classified according to the modified Scheuer-classification for staging fibrosis and inflammation [29, 30]. Aspartate aminotransferase (AST)-to-platelet ratio index (APRI) and fibrosis-4 score (FIB-4) were calculated as serological markers of fibrosis over the study period [31-33]. In addition, within the scope of screening and clinical observation magnetic-resonance imaging and clinical ultrasound were performed.

\section{Statistical analysis}

For efficacy endpoints all patients were included who received at least one dose of study medication (modified intention to treat population). This is an explorative proof of concept study with a calculated sample size of $n=14$ patients (power 90\% with a type I error of $5 \%$ (type II error $=10 \%$ ) for an estimated efficacy of $79 \%$ SVR12. During the course of the study it was decided to enroll 2 additional patients, which even further increases the power of this study to demonstrate adequate efficacy in this population.

Statistical software SPSS version 22 and GraphPad Prism Version 7.0 were used for data analyses.

\section{Results}

\section{Study population}

Amongst 1365 KTR that were regularly followed in our outpatient clinic, we identified 32 (2.3\%) chronic HCV-infected patients, $n=2$ with GT1a and $n=30$ with GT1b respectively. The screening process to identify the target population for this study is summarized in Fig. 2.

Initially, 18 patients met all inclusion criteria and were willing to participate in the study. However, two patients withdrew their consent to participate in the study immediately before any study related procedure was initiated. Therefore, 16 patients received treatment and comprised the study population. Baseline characteristics are shown in Table 1.

\section{Efficacy and virological response}

Mean time to viral clearance was 4 weeks after start of treatment. At EOT, HCV RNA was undetectable in all patients. However, 1 KTR (with genotype 1a) showed viral relapse at week 4 after EOT (time 


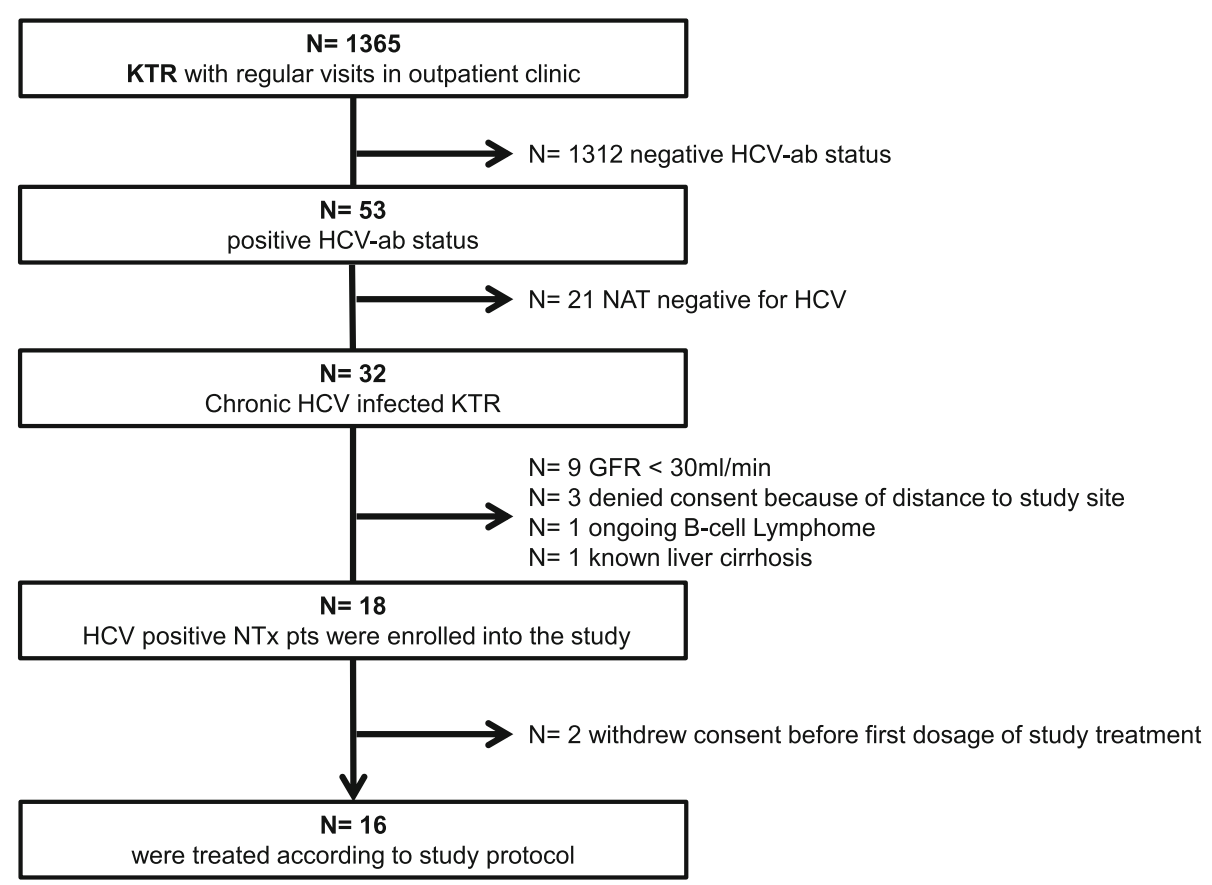

Fig. 2 Patient screening strategy to identify study target population

course of viral clearance is shown in Fig. 3). In this patient DCV/SOF, combination therapy was prolonged according to the study protocol for another 12-weeks course. Again, the patient had undetectable HCV RNA at EOT and an early viral relapse 4 weeks later. At this time point ultra-deep sequencing analysis revealed resistance-associated variants (RAVs) for $\mathrm{M} 28-\mathrm{V}$ and $\mathrm{Q} / \mathrm{R} 30-\mathrm{R}$ in the NS5A region of the $\mathrm{HCV}$ genome in this non-responding patient. In summary, 15 of 16 (94\%) KTR achieved SVR4, SVR12 and SVR24 after completion of primary protocol with DCV/SOF.

\section{Rescue therapy}

During the course of this study a new DAA combination therapy containing SOF $(400 \mathrm{mg})$, velpatasvir (VEL, $100 \mathrm{mg}$ ), a NS5A inhibitor, and voxilaprevir (VOX, $100 \mathrm{mg}$ ), a novel NS3/4A protease inhibitor, was approved for treatment of $\mathrm{HCV}$ patients with treatment failure [34]. We initiated this novel therapeutic rescue therapy in the patient with early viral relapse and confirmed RAVs in the NS5A region. After rapid virus decline (HCV RNA not detectable at week 4) HCV RNA has so far remained undetectable in this patient for 12 weeks after EOT.

\section{Safety data}

Overall, DCV/SOF therapy was well tolerated in all 16 KTR with no SUSARs over the study period. In 14 KTR 77 AEs and in 4 KTR 8 SAEs occurred (see Table 2). Five
AEs were categorized as suspected to be related to study drug (nausea, reflux and fatigue); no SAE considered as related to the study drug was noticed and no drug discontinuation occurred.

One patient presented with an accidental finding of a post-transplant proliferative lymphoprolferative disease (PTLD) in the initial liver biopsy. At this time point no clinical or laboratory findings were suggestive for an underlying malignancy. In the performed staging CT scan no further extra hepatic PTLD manifestation could be identified. We decided to pursue with DCV/SOF therapy and the patient reached SVR12. After the end of the study patient was treated with four cycles of rituximab (Mabthera ${ }^{\circ} 500 \mathrm{mg}$ ). In the follow-up liver biopsy (3 months after end of study) PTLD was no longer detectable.

Regarding graft function, we could not detect any signs of deterioration in renal transplant function, nor any significant changes in proteinuria levels or signs for rejection episodes.

\section{CNI metabolism}

We documented on average an increase of daily dosages of TAC $(+34.5 \%)$ and CyA $(+21.6 \%)$ over the study period. In $4 / 7$ TAC-treated patients an increase of daily dosage was noted. In one patient no changes were necessary and in one patient the dose was decreased after initiation of DCV/SOF. Similarly, in 5/8 CyA-treated patients CyA doses were increased. Again, in one patient CyA dose remained unchanged and in one patient CyA was reduced. In another 
Table 1 Demographic and Baseline Characteristics

\begin{tabular}{|c|c|}
\hline Median Age (range), y & $51.5(34-75)$ \\
\hline Sex, male, n (\%) & $8(50)$ \\
\hline $\begin{array}{l}\text { Median time since kidney } \\
\text { transplantation (range), y }\end{array}$ & $12.8(2.3-25.8)$ \\
\hline $\begin{array}{l}\text { Number of previous renal } \\
\text { transplantations }\left(1^{\text {st }} / 2^{\text {nd }} / 3^{\text {rd }} / 4^{\text {th }}\right)\end{array}$ & $4 / 11 / 0 / 1$ \\
\hline \multicolumn{2}{|l|}{ Cause of end-stage renal disease, $\mathrm{n}$} \\
\hline Chronic Glomerulonephritis & 5 \\
\hline Polycystic Kidney Disease & 3 \\
\hline Alport-Syndrome & 4 \\
\hline Interstitial Nephritis & 3 \\
\hline Unknown & 1 \\
\hline \multicolumn{2}{|l|}{$\begin{array}{l}\text { CMV antibody status: } \\
\text { (Donor }(\mathrm{D}+/-) / \text { Recipient }(\mathrm{R}+/-) ; \mathrm{n}\end{array}$} \\
\hline Low-risk $(D-/ R+)$ & 4 \\
\hline Intermediate risk $(\mathrm{D}+/ \mathrm{R}+)$ & 10 \\
\hline High-risk (D + / R -) & 2 \\
\hline $\begin{array}{l}\text { EBV antibody status: } \\
(\mathrm{D} \text { unknown } / \mathrm{R}+\text { ) }\end{array}$ & 16 \\
\hline \multicolumn{2}{|l|}{ Type of Immunsuppressive used, n (\%) } \\
\hline Tacrolimus & $8(50)$ \\
\hline Cyclosporine & $7(44)$ \\
\hline Sirolimus & $1(6)$ \\
\hline Mycophenolate & $14(88)$ \\
\hline Azathioprine & $1(6)$ \\
\hline Steroids & $6(38)$ \\
\hline \multicolumn{2}{|l|}{ Renal Transplant function } \\
\hline Median Creatinine, mg/dl & $1.27(0.95-2.3)$ \\
\hline Median eGFR, ml/min per $1.73 \mathrm{~m}^{2}$ & $60(25-87)$ \\
\hline \multicolumn{2}{|l|}{ HCV genotype, $n$} \\
\hline la & 1 \\
\hline $\mathrm{lb}$ & 15 \\
\hline Median HCV RNA level (range), $\log _{10} \mathrm{IU} / \mathrm{ml}$ & $1.19 E^{6}\left(36600-9.4 E^{6}\right)$ \\
\hline Previous HCV therapy (pegINF and/or ribavirin) n/N & $4 / 16$ \\
\hline \multicolumn{2}{|l|}{ Stage of Liver disease } \\
\hline Liver biopsy available, $\mathrm{n} / \mathrm{N}$ & $14 / 16$ \\
\hline \multicolumn{2}{|l|}{ Stage of Fibrosis, n/N } \\
\hline - No or minimal (F0, F0-F1, or F1) & $2 / 14$ \\
\hline - Moderate (F1-F2 or F2) & $10 / 14$ \\
\hline - Severe (F3) & $2 / 14$ \\
\hline Median body mass index (range), $\mathrm{kg} / \mathrm{m}^{2}$ & $21.47(16.43-31.25)$ \\
\hline
\end{tabular}

patient with a sirolimus-based immunosuppressive regimen no adaptation was necessary.

To further specify the drug metabolism we assessed the $\mathrm{C} / \mathrm{D}$ ratio of TAC- $(n=7)$ and $\mathrm{CyA}-(n=8)$ treated patients. After initiation of therapy TAC $\mathrm{C} / \mathrm{D}$ ratio declined over the study period (BL: $4.33+/-1.5$; EOT: 2.85+/-0.84; SVR12: 2.49+/-0.76; SVR24: 3.12+/-2.19; (mean $+/-\mathrm{SD} ; p=0.003$, Friedman test, see Fig. 4a).

In CyA treated patients the course of C/D scores was similar: BL: $1.31+/-0.71$; EOT: $0.89+/-0.23$; SVR12: $\quad 0.79+/-0.21 ; \quad$ SVR24: $0.57+/-0.23 ; \quad$ (mean $+/$ SD; $p=0.0001$, Friedman test, see Fig. 4b). Thus, therapy with DCV/SOF apparently increased the metabolism of both CNIs. Reduced C/D scores were documented for both CNIs until the end of study (week 36/SVR24).

\section{Hepatic function}

In 14 of 16 patients a liver biopsy was performed at BL (two patients dropped out; one of them due to advanced polycystic liver disease, one withdrew consent). Histopathology in the 14 patients showed a median fibrosis score of 2 (shown in Table 1), a median inflammation score of 1 and a medium fat deposition of 5\% (modified Scheuer-classification).

Changes of laboratory values are displayed in Table 3. Liver parameters (ALT and AST) as well as ferritin levels improved significantly after $\mathrm{HCV}$ treatment $(p<0.0001)$. APRI $(0.47+/-0.22$ vs. $0.25+/-0.11$; (mean $+/-\mathrm{SD}) ; p=0.001)$ and FIB-4 score $(1.45+/-0.63$ vs. $1.19+/-0.53$; (mean +/-SD); $p=0.023)$ also improved significantly over the study period. There were no significant changes in conventional MRI or ultrasound imaging during the study (data not shown).

\section{Glucose tolerance}

One patient was excluded from the analysis because of preexisting diabetes mellitus type I. Initial performed OGTT at baseline identified one patient with PTDM ( 2 h-gluc $\geq 200$ $\mathrm{mg} / \mathrm{dl}$ ) and four patients with IGT ( $2 \mathrm{~h}$-gluc $\geq 140 \mathrm{mg} / \mathrm{dl}$ ), whereas all the other 10 patients had OGTTs within normal limits. Further evaluations at SVR12 provided pre diabetic values in scheduled OGTTs in two out of 14 patients only. One patient did not consent to the SVR12 OGTT. ANOVA demonstrated OGTT-derived $2 \mathrm{~h}$-glucose differed significantly between scheduled visits (Wilks-Lamdba $=0.405, \mathrm{~F}(2$, $11)=8.081, p=0.007)$. At BL mean $2 \mathrm{~h}$-glucose was $141 \pm 77$ $\mathrm{mg} / \mathrm{dl}, 132 \pm 52 \mathrm{mg} / \mathrm{dl}$ at EOT and $117 \pm 77 \mathrm{mg} / \mathrm{dl}$ at SVR12. Finally, between BL and SVR12 paired samples t-test confirmed significant differences in $2 \mathrm{~h}$-glucose.

We did not find any statistical significant changes in HOMA2-IR/-B (Table 3), but results directed to improved insulin sensitivity and decreased beta cell output correspondingly. This reflects consistency with overall improved glucose tolerance.

\section{Discussion}

Here we present the first prospective, open-label study with a DCV/SOF based DAA regimen in chronically HCV-infected KTR. Our data shows that the use of this 


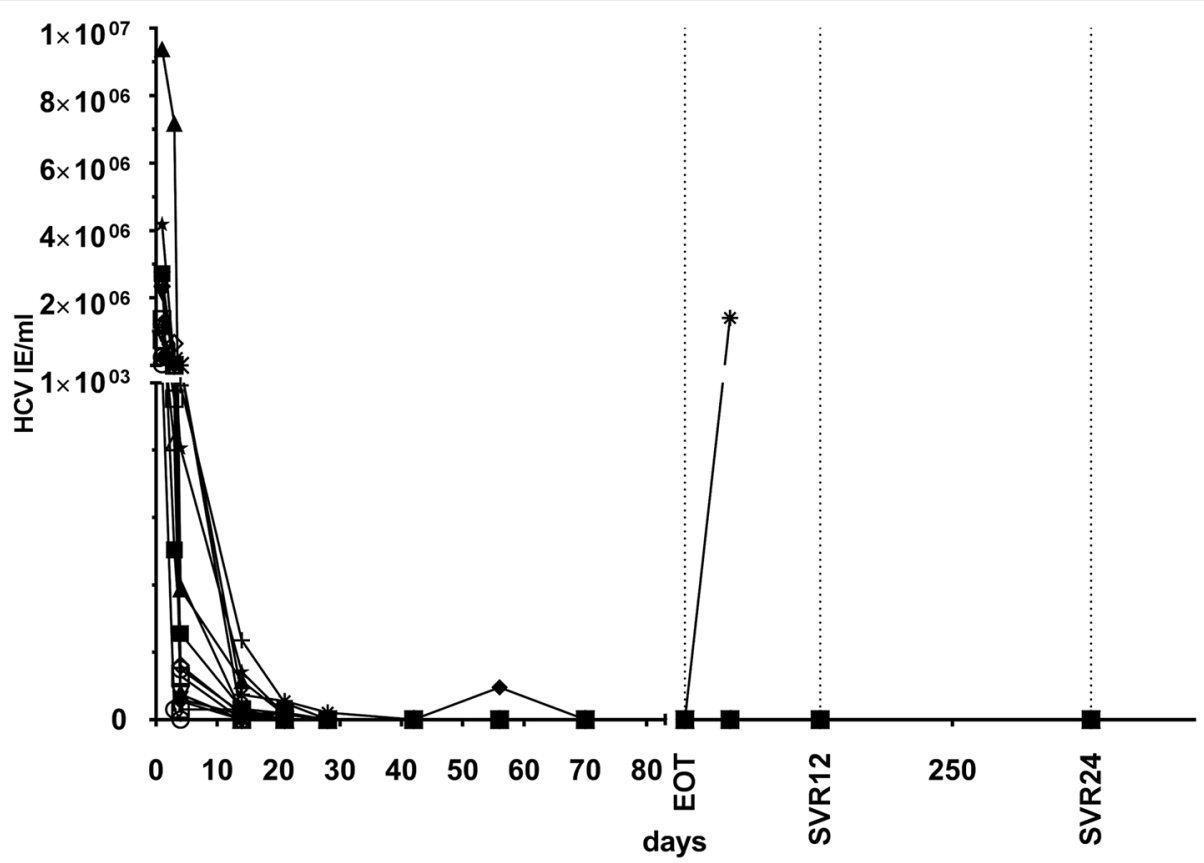

Fig. 3 Efficacy of DCV/SOF treatment. HCV-RNA viral load in 16 HCV-positive KTR over the treatment period with DCV/SOF

pan-genotypic combination therapy is safe and effectively cures chronic and long-standing $\mathrm{HCV}$ disease in KTR with GFR $>30 \mathrm{ml} / \mathrm{min} / 1.73 \mathrm{~m}^{2}$ and no signs of advanced liver disease.

In total, 15/16 KTR (94\%) achieved SVR12 with DCV/ SOF combination. In these "responders", we noticed early viral response, defined as a rapid virus clearance already after a median of 4 weeks after initiating DCV/ SOF therapy. One patient achieved negative HCV PCR at EOT but had early viral relapse 4 weeks after EOT. Based on the protocol a second 12-weeks therapy extension with DCV/SOF was performed, but the patient developed another early viral relapse. Deep sequencing HCV genome analysis revealed RAVs to all available viral NS5A inhibitors [35]. Therefore, we administered a 12-weeks course of SOF/VEL/VOX (Vosevi ${ }^{\circ}$ ). This fix dose regimen was approved by the FDA on July 18th, 2017 for patients with any genotype of chronic HCV infection, without cirrhosis or with compensated cirrhosis and previously failed therapy with a DAAs-containing regimen [34]. Here we report the first successful treatment with this novel combination therapy as a rescue therapy in a KTR with chronic $\mathrm{HCV}$ infection and detected NS5A-RAVs.

Over the entire study period we reported 77 AEs, 8 were categorized as SAE. Until EOT, 43 AEs and 2 SAEs were documented. However, in only three study subjects mild AEs were categorized as drug-related, which reflect excellent tolerability of DCV/SOF. In no case the drug regimen was discontinued. In addition, we noticed stable graft function without any evidence for BPARs or worsening of proteinuria over the study period. Our findings are in contrast to Lubetzky et al. who most recently reported a retrospective analysis of 31 KTR with

Table 2 Safety Lab values

\begin{tabular}{|c|c|c|c|c|}
\hline $\begin{array}{l}\text { Lab value, } \\
\text { (unit) }\end{array}$ & $\begin{array}{l}\text { Baseline, mean } \\
(+/ \text {-SD })\end{array}$ & $\begin{array}{l}\text { EOT, mean } \\
(+/ \text {-SD })\end{array}$ & $\begin{array}{l}\text { SVR12, mean } \\
(+/-S D)\end{array}$ & $\begin{array}{l}\text { p (one-way } \\
\text { ANOVA) }\end{array}$ \\
\hline$\overline{\mathrm{ALT}(\mathrm{U} / \mathrm{I})}$ & $48.31(31.71)$ & $20.56(10.52)$ & $19.06(7.88)$ & $<0.0001$ \\
\hline AST (U/l) & 42.06 (16.78) & 27.75 (12.37) & $23.0(12.37)$ & $<0.0001$ \\
\hline $\mathrm{AP}(\mathrm{U} / \mathrm{l})$ & $87.06(40.25)$ & 79.69 (40.93) & $82.50(46.18)$ & 0.89 \\
\hline GGT (U/I) & $146.13(282.40)$ & $55.00(115.15)$ & $53.94(116.97)$ & 0.29 \\
\hline $\begin{array}{l}\text { Bilirubin, total } \\
(\mathrm{mg} / \mathrm{dl})\end{array}$ & $0.48(0.22)$ & $0.31(0.16)$ & $0.47(0.29)$ & 0.068 \\
\hline Albumin $(\mathrm{g}(\mathrm{l})$ & $42.97(3.48)$ & $43.14(3.48)$ & $42.67(4.79)$ & 0.944 \\
\hline $\mathrm{Hb}(\mathrm{g} / \mathrm{dl})$ & $12.9(1.5)$ & $12.1(1.35)$ & $12.57(1.52)$ & 0.31 \\
\hline Ferritin $(\mu \mathrm{g} / \mathrm{l})$ & $253.38(163.37)$ & $124.11(64.37)$ & $127.33(63)$ & 0.002 \\
\hline HbA1c (\%) & $5.59(0.93)$ & $5.33(0.52)$ & $5.54(0.95)$ & 0.65 \\
\hline TG (mg/dl) & $145.5(85.58)$ & $147.13(88.45)$ & 136.06 (91.02) & 0.93 \\
\hline $\mathrm{HDL}(\mathrm{mg} / \mathrm{dl})$ & 53.69 (18.54) & $55.44(15.22)$ & $55.81(15.18)$ & 0.93 \\
\hline CRP (mg/l) & $2.44(2.71)$ & $3.95(5.82)$ & $3.04(3.22)$ & 0.59 \\
\hline $\begin{array}{l}\text { creatinine } \\
(\mathrm{mg} / \mathrm{dl})\end{array}$ & $1.41(0.44)$ & $1.52(0.50)$ & $1.54(0.51)$ & 0.71 \\
\hline $\begin{array}{l}\text { proteinuria } \\
\text { (mg/g } \\
\text { creatinine) }\end{array}$ & $605.63(1240.54)$ & $374.94(549.25)$ & 440.94 (689.55) & 0.75 \\
\hline HOMA2-IR & $89.22(33.77)$ & $103.3(36.46)$ & $113.54(70.35)$ & 0,24 \\
\hline HOMA2-B & 128.01 (91.83) & $114.21(63.68)$ & 111.55 (71.23) & 0,63 \\
\hline
\end{tabular}




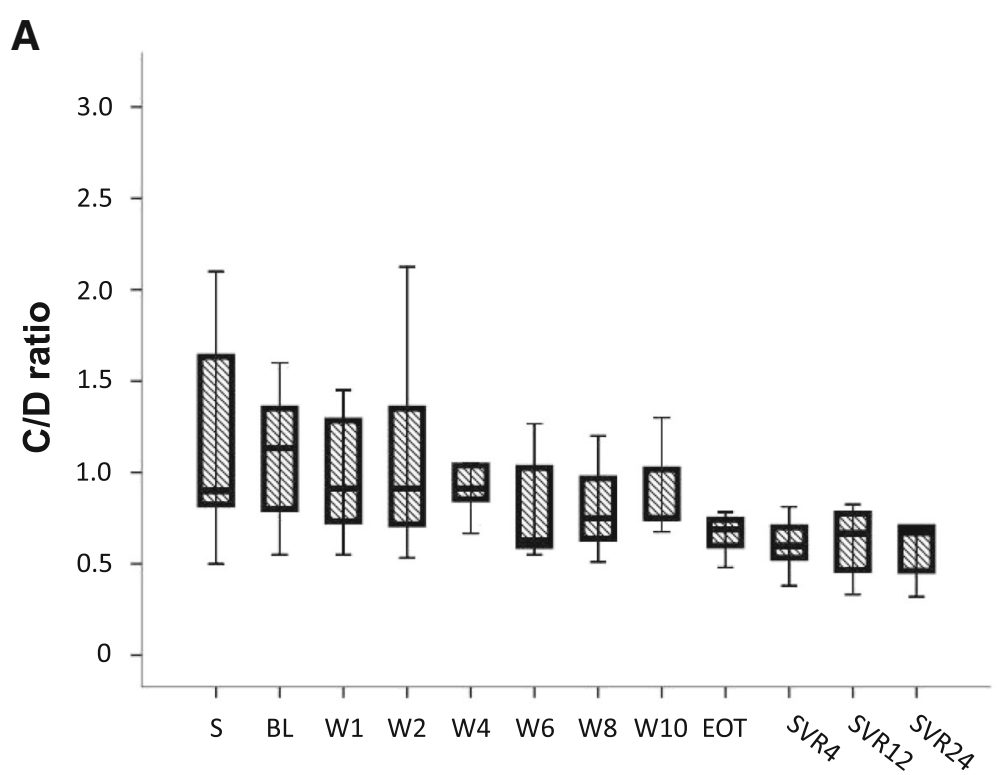

B

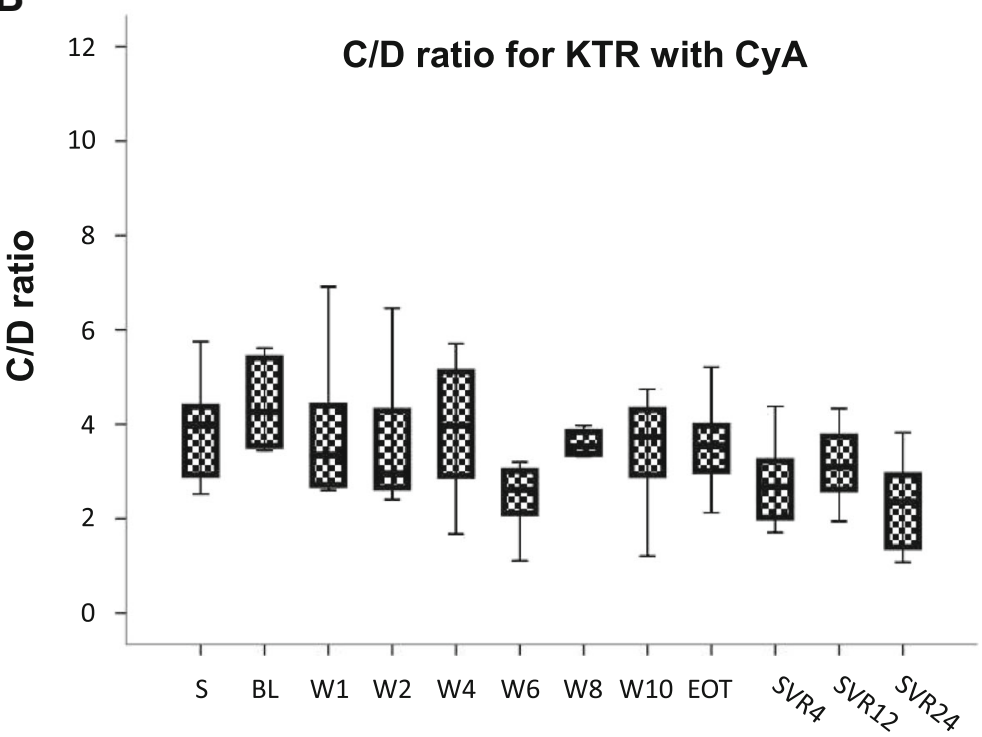

Fig. 4 a C/D ratio for KTR with TAC. Dose normalized drug trough level concentration (C) to the daily TAC dose (D) is shown. $S=$ screening visit, $\mathrm{BL}=$ baseline, $\mathrm{W}=$ week, $\mathrm{EOT}=$ End of therapy, $\mathrm{SVR}=$ Sustanied virological response. $\mathbf{b} \mathrm{C} / \mathrm{D}$ ratio for $\mathrm{KTR}$ with CyA. Dose normalized drug trough level concentration (C) to the daily CyA dose (D) is shown. $S=$ screening visit, BL = baseline, $W=$ week, EOT = End of therapy, SVR= Sustanied virological response

worsening of pre-existing proteinuria and a decline of renal function under DAAs therapy [36].

Because blood levels of CyA or TAC may be affected by drug-drug interactions, dosages and trough levels were analyzed prospectively. As per center practice, the maintenance immunosuppressive regimen of all patients was continued during this study. We found significant changes in the TAC and CyA C/D ratios in the blood after initiation of DCV/SOF. Due to lower trough levels of immunosuppressants daily dosage of TAC and CyA in most patients were increased over the study course.
Dose normalized ratios for TAC and CyA were further decreasing after EOT until the end of study. These findings are in line with other published cohorts [22, 37]. Of note, neither SOF nor DCV interacts directly with cytochrome $\mathrm{P} 450$, in fact this pan-genotypic combination therapy seems very favorable in terms of drug-drug interactions in KTR [38]. We rather speculate that improvement of hepatic function increased the ability of CYP3A4 to metabolise TAC and CYA, resulting in higher dose requirements to reach target levels in study participants. 
Table 3 Safety Analysis and overall Adverse Events

\begin{tabular}{|c|c|c|c|c|}
\hline \multirow[b]{2}{*}{ Parameter } & \multicolumn{2}{|c|}{$\mathrm{DCV}+\operatorname{SOF}(\mathrm{n}=16)$} & & \\
\hline & until EOT & until end of study & & \\
\hline No. of all AEs & 43 & 77 & & \\
\hline AEs suspected of being related to study drug & 5 & 5 & & \\
\hline No. of SAES & 2 & 8 & & \\
\hline No. of SAEs which were in relation to study drug & 0 & 0 & & \\
\hline No. of patients with one or more $\mathrm{AE}$ & 12 & 14 & & \\
\hline No. of patients with one or more SAE & 2 & 4 & & \\
\hline \multirow[t]{2}{*}{ No. of patients who needed hospitalization } & 2 & 7 & & \\
\hline & & & AE Drug related & SAE \\
\hline Gastrointestinal events, no., (\% of al AEs) & $5(11.63 \%)$ & $6(7.79 \%)$ & & \\
\hline Nausea & 3 & 3 & yes & \\
\hline Diarrhea & 1 & 1 & & \\
\hline Gastro-enteritis & 2 & 2 & & \\
\hline Reflux/Gastritis & 1 & 2 & yes & \\
\hline Infection related events, no. (\% of all AEs) & $17(39.53 \%)$ & 31 (40.26\%) & no & \\
\hline Urinary tract infection & 5 & 9 & & 2 \\
\hline Sepsis, 3-MRGN & 0 & 1 & & 1 \\
\hline C. difficile infection & 1 & 1 & & 1 \\
\hline Common cold & 4 & 10 & & \\
\hline Pneumonia/Bronchitis & 2 & 3 & & 1 \\
\hline Fever & 1 & 2 & & \\
\hline Conjunctivitis & 0 & 1 & & \\
\hline Epiglottitis & 1 & 1 & & \\
\hline Tonsillar angina & 1 & 1 & & \\
\hline No. of any Efficacy failure (\%) of patients & $0(0 \%)$ & $1(6.25 \%)$ & & \\
\hline Viral breakthrough & 0 & 0 & & \\
\hline Viral relapse & 0 & 1 & & 1 \\
\hline Any Malignancies or any suspected Neoplasia, no.(\%) of patients" & $1(6.25 \%)$ & $2(12.5 \%)$ & & \\
\hline PTLD* in liver & 1 & 1 & & \\
\hline Follow-up liver biopsy & 0 & 1 & & 1 \\
\hline Pituitary adenoma & 0 & 1 & & 1 \\
\hline Any Heart, Cardiovascular, no. (\%) of all AEs & $2(4.65 \%)$ & $2(2.6 \%)$ & & \\
\hline Tachycardia & 1 & 1 & & \\
\hline Hypertension & 1 & 1 & & \\
\hline Any Neurological events, no. (\%) of all AEs & $4(9.3 \%)$ & $9(11.69 \%)$ & & \\
\hline Concentration weakness & 1 & 2 & & \\
\hline Headache & 3 & 4 & & \\
\hline Dizziness & 0 & 1 & & \\
\hline Hyposphagma & 0 & 1 & & \\
\hline No. of any other AE. (\%) of patients & $14(32.56 \%)$ & 26 (33.77\%) & & \\
\hline Asthma episode/ Dyspnoe & 1 & 5 & & \\
\hline Myalgia & 2 & 4 & & \\
\hline Lower back pain & 2 & 3 & & \\
\hline Fatigue & 1 & 2 & yes & \\
\hline Anemia/Iron deficiency & 3 & 3 & & \\
\hline Alopecia & 1 & 1 & & \\
\hline Leukocytosis & 1 & 1 & & \\
\hline Urinary incontinence & 1 & 1 & & \\
\hline Hyperkaliemia & 0 & 1 & & \\
\hline Hypercalcemia & 0 & 1 & & \\
\hline Edema & 2 & 2 & & \\
\hline Pancreatic cyst & 0 & 1 & & \\
\hline Rib fracture & 0 & 1 & & \\
\hline
\end{tabular}


At study entry, most of the patients showed moderate signs of liver fibrosis and hepatic inflammation in the liver biopsy. In MRI and ultrasound no signs for liver cirrhosis were detectable in our population. During the study we found a significant improvement of liver function displayed by a significant reduction of initially elevated liver enzymes and improvement of APRI and FIB-4 scores. However, ultrasound and MRI showed no significant differences over the study period.

Patients with chronic HCV infection also frequently show serum and hepatic iron overload due to lower hepcidin levels [39]. During our study we found a significant reduction of ferritin levels after successful cure of $\mathrm{HCV}$ infection, which might be caused by improved hepatic function after HCV treatment.

One patient showed incidental asymptomatic $\mathrm{HCV}$ associated B-cell lymphoma in the initial biopsy finding. We decided to proceed with the planned study protocol as a potential causative treatment option. The patient received rituximab as a specific PTLD treatment after the end of study. Follow-up MRI and liver biopsy, which was performed 3 months after end of study, showed no signs of PTLD. Although it is well established that regression of $\mathrm{HCV}$ associated lymphatic disorders is closely correlated with viral clearance at least with interferon-based antiviral therapy, data on resolution of PTLD after treatment with DAAs are very limited so far $[40,41]$.

$\mathrm{HCV}$ infection is known to induce metabolic changes, such as insulin resistance and beta-cell dysfunction [42]. Virus clearance improves insulin resistance, $\beta$-cell function, and hepatic expression of insulin receptor substrate 1 and 2 [43]. Clinically relevant improvements in glucose tolerance have been shown in the non-transplant population by OGTT [44]. KTR are particularily vulnerable to develop PTDM when HCV infection coincides.

OGTT is the preferred method to assess carbohydrate tolerance in stable KTR and allows for diagnosis of IGT, an independent risk factor of subsequent PTDM [26]. Within this trial, KTR previously in the pre-diabetic range returned to normal glucose tolerance. Among all patients, 2-h glucose improved significantly. In addition, we noticed a trend for improvement in HOMA2-IR/-B scores. As PTDM is the principal determinant of death with functioning graft after kidney transplantation, this antidiabetic effect could possibly translate into improvement of overall outcomes.

Our study has some limitations. Although currently the largest prospective trial in KTR with DCV/SOF, the number of 16 treated patients is still relatively small. In addition, further follow-up will have to proof sustained viral clearance and functional improvement. Given the nature of the intervention, the small size of the study population and the availability of objective response parameters, we decided to implement an un-controlled open-label design. The study population had mostly GT1b HCV infection and the relevance for other genotypes has to be determined. The strength of the study includes the prospective design, the systematic assessment of AEs and the measurement of both, viral response and functional parameters.

\section{Conclusions}

Our study shows safety and efficacy of DAAs in KTR. Based on the observed functional improvements there appears to be potential benefit for clinical outcomes. However, mostly because of improvement of liver function careful surveillance of immunosuppressive trough levels appears mandatory, as the necessity for dose adjustments is common. We recommend testing for RAVs prior to start of a specific DAAs regimen. As "second-line" DAAs for patients with previously failed DAAs therapy are nowadays available, there are also treatment options for non-responders and relapsers. Moreover, the acceptance of $\mathrm{HCV}$ positive donor organs for $\mathrm{HCV}$ negative transplant candidates is an option that deserves further studies [45].

\section{Abbreviations \\ AEs: Adverse events; APRI: AST to-platelet ratio index; AST: Aspartate aminotransferase; BPAR: Biopsy proven rejections; CyA: Ciclosporin A; DAA: Direct acting antiviral; DCV: Daclatasvir; EOT: End of treatment; FIB- 4: Fibrosis-4 score; HCV: Hepatitis C Virus; HOMA2-IR/-B: Homeostatic model assessment indexes were assessed to identify insulin resistance and $\beta$-cell function; IGT: Impaired glucose tolerance; KTR: Kidney transplant recipient; NAT: Nucleic acid testing; OGTT: Oral glucose tolerance test; pegIFN: Pegylated interferon; PTDM: Post-transplantat diabetes mellitus; PTLD: Post-transplant lyphoproliferative disease; RBV: Ribavirin; SAEs: Serious AEs; SOF: Sofosbuvir; SUSAR: Suspected unexpected severe adverse reaction; SVR: Sustained virological response; TAC: Tacrolimus; ULN: Upper limit of normal; VEL: Velpatasvir; VOX: Voxilaprevir}

\section{Acknowledgements}

E.S. is participant in the Charite Junior Clinician Scientist program.

\section{Funding}

Bristol-Myers Squibb (BMS) funded the study. BMS had no role in the conception of the trial design, the assessment, analysis, or neither interpretation of data nor the writing of the manuscript. The authors guarantee for the accuracy and completeness of data and analyses of this trial.

\section{Availability of data and materials}

No data has been submitted to any open access databases. The datasets were created and analysed during the current study. Datasets are available from the corresponding author on reasonable request.

\section{Authors' contributions}

Conception or design, or analysis and interpretation of data, or both: $\mathrm{MD}, \mathrm{FH}$ and KB. Drafting the article or revising it: FH, LL, LB, ES, KE, KB and MD. Providing intellectual content of critical importance to the work described: $M D, S M, C A, I S, P G, S B, K E, K B, M D$ and FH. Final approval of the version to be published: $M D, E S, L L, L B, P G, S M, C A, I S, S B, K E, K B$ and $F H$. All authors read and approved the final manuscript. 


\section{Ethics approval and consent to participate}

All patients provided written informed consent. The study protocols were conducted in compliance with German law and approved by the independent ethics committee at the "Landesamt für Gesundheit und Soziales" of the state Berlin (approval number: 15/0446EK15) and the Federal Institute for Drugs and Medical Devices (approval number: 4040892).

All procedures followed in the trials were in accordance with the Declaration of Helsinki, the International Conference on Harmonization and Good Clinical Practice guidelines.

\section{Consent for publication}

Not applicable.

\section{Competing interests}

Michael Duerr received a travel grant and speakers honoraria from BMS, Novartis, Roche and Astellas.

Eva V. Schrezenmeier has no conflict of interest to declare.

Lukas L. Lehner has no conflict of interest to declare.

Leon Bergfeld has no conflict of interest to declare.

Petra Glander has no conflict of interest to declare.

Stephan R. Marticorena has no conflict of interest to declare.

Christian E. Althoff has no conflict of interest to declare.

Ingolf Sack has no conflict of interest to declare.

Susanne Brakemeier has no conflict of interest to declare.

Kai-Uwe Eckardt has no conflict of interest to declare.

Klemens Budde has received research funds and/or honoraria from Abbvie, Alexion, Astellas, Bristol-Myers Squibb, Chiesi, Fresenius, Genentech, Hexal, Novartis, Otsuka, Pfizer, Roche, Shire, Siemens, and Veloxis Pharma.

Fabian Hallck has no conflict of interest to declare.

\section{Publisher's Note}

Springer Nature remains neutral with regard to jurisdictional claims in published maps and institutional affiliations.

\section{Author details}

'Department of Nephrology and Medical Intensive Care, Charité Universitätsmedizin Berlin, Augustenburger Platz, 13353 Berlin, Germany. ${ }^{2}$ Department of Radiology, Charité Universitätsmedizin Berlin, Berlin, Germany.

Received: 10 October 2018 Accepted: 17 January 2019 Published online: 04 February 2019

\section{References}

1. Fabrizi F, Martin P, Dixit V, Messa P. Meta-analysis of observational studies: hepatitis C and survival after renal transplant. J Viral Hepat. 2014;21(5):314-24.

2. Mathurin P, Mouquet C, Poynard T, Sylla C, Benalia H, Fretz C, et al. Impact of hepatitis $B$ and $C$ virus on kidney transplantation outcome. Hepatology. 1999:29(1):257-63.

3. Bruchfeld A, Wilczek $H$, Elinder CG. Hepatitis C infection, time in renalreplacement therapy, and outcome after kidney transplantation. Transplantation. 2004;78(5):745-50.

4. Baid-Agrawal S, Pascual M, Moradpour D, Somasundaram R, Muche M. Hepatitis C virus infection and kidney transplantation in 2014: what's new? Am J Transplant. 2014;14(10):2206-20.

5. Terrault NA, Adey DB. The kidney transplant recipient with hepatitis $C$ infection: pre- and posttransplantation treatment. Clin J Am Soc Nephrol. 2007;2(3):563-75.

6. Fabrizi F, Dixit V, Messa P. Impact of hepatitis $C$ on survival in dialysis patients: a link with cardiovascular mortality? J Viral Hepat. 2012;19(9):601-7.

7. Lee MH, Yang HI, Lu SN, Jen CL, You SL, Wang LY, et al. Chronic hepatitis C virus infection increases mortality from hepatic and extrahepatic diseases: a community-based long-term prospective study. J Infect Dis. 2012;206(4): 469-77.

8. Manns MP, McHutchison JG, Gordon SC, Rustgi VK, Shiffman M, Reindollar R, et al. Peginterferon alfa-2b plus ribavirin compared with interferon alfa- $2 \mathrm{~b}$ plus ribavirin for initial treatment of chronic hepatitis $\mathrm{C}$ : a randomised trial. Lancet. 2001;358(9286):958-65.

9. Sawinski D, Bloom RD. Novel hepatitis $C$ treatment and the impact on kidney transplantation. Transplantation. 2015;99(12):2458-66.
10. Poordad F, McCone J Jr, Bacon BR, Bruno S, Manns MP, Sulkowski MS, et al. Boceprevir for untreated chronic HCV genotype 1 infection. N Engl J Med. 2011;364(13):1195-206

11. Jacobson IM, McHutchison JG, Dusheiko G, Di Bisceglie AM, Reddy KR, Bzowej $\mathrm{NH}$, et al. Telaprevir for previously untreated chronic hepatitis C virus infection. N Engl J Med. 2011;364(25):2405-16.

12. Kulkarni S, Kirkiles-Smith NC, Deng YH, Formica RN, Moeckel G, Broecker V, et al. Eculizumab therapy for Chronic antibody-mediated injury in kidney transplant recipients: a pilot randomized controlled trial. Am J Transplant. 2017; 17(3):682-91.

13. Gehring S, Gregory SH, Wintermeyer P, Aloman C, Wands JR. Generation of immune responses against hepatitis $C$ virus by dendritic cells containing NS5 protein-coated microparticles. Clin Vaccine Immunol. 2009;16(2):163-71.

14. Nelson DR, Cooper JN, Lalezari JP, Lawitz E, Pockros PJ, Gitlin N, et al. Alloral 12-week treatment with daclatasvir plus sofosbuvir in patients with hepatitis C virus genotype 3 infection: ALLY-3 phase III study. Hepatology. 2015;61(4):1127-35.

15. Sulkowski MS, Gardiner DF, Rodriguez-Torres M, Reddy KR, Hassanein T, Jacobson I, et al. Daclatasvir plus sofosbuvir for previously treated or untreated chronic HCV infection. N Engl J Med. 2014;370(3):211-21.

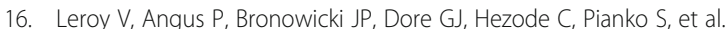
Daclatasvir, sofosbuvir, and ribavirin for hepatitis $C$ virus genotype 3 and advanced liver disease: a randomized phase III study (ALLY-3+). Hepatology. 2016;63(5):1430-41.

17. Luetkemeyer AF, McDonald C, Ramgopal M, Noviello S, Bhore R, Ackerman P. 12 weeks of Daclatasvir in combination with Sofosbuvir for HIV-HCV coinfection (ALLY-2 study): efficacy and safety by HIV combination antiretroviral regimens. Clin Infect Dis. 2016;62(12):1489-96.

18. Sawinski D, Kaur N, Ajeti A, Trofe-Clark J, Lim M, Bleicher M, et al. Successful treatment of hepatitis $C$ in renal transplant recipients with direct-acting antiviral agents. Am J Transplant. 2016;16(5):1588-95.

19. Kamar N, Marion O, Rostaing L, Cointault O, Ribes D, Lavayssiere L, et al. Efficacy and safety of Sofosbuvir-based antiviral therapy to treat hepatitis C virus infection after kidney transplantation. Am J Transplant. 2016;16(5): 1474-9.

20. Eisenberger U, Guberina $H$, Willuweit K, Bienholz A, Kribben A, Gerken $G$, et al. Successful treatment of chronic hepatitis $C$ virus infection with sofosbuvir and ledipasvir in renal transplant recipients. Transplantation. 2017;101(5):980-6. https://doi.org/10.1097/TP 0000000000001414

21. Fernandez I, Munoz-Gomez R, Pascasio JM, Baliellas C, Polanco N, Esforzado $\mathrm{N}$, et al. Efficacy and tolerability of interferon-free antiviral therapy in kidney transplant recipients with chronic hepatitis C. J Hepatol. 2017;66(4):718-23.

22. Colombo M, Aghemo A, Liu H, Zhang J, Dvory-Sobol H, Hyland R, et al. Treatment with Ledipasvir-Sofosbuvir for 12 or 24 weeks in kidney transplant recipients with Chronic hepatitis C virus genotype 1 or 4 infection: a randomized trial. Ann Intern Med. 2017;166(2):109-17.

23. Levey AS, Stevens LA, Schmid CH, Zhang YL, Castro AF 3rd, Feldman HI, et al. A new equation to estimate glomerular filtration rate. Ann Intern Med. 2009;150(9):604-12.

24. Hasin D, Hatzenbuehler ML, Keyes K, Ogburn E. Substance use disorders: diagnostic and statistical manual of mental disorders, fourth edition (DSMIV) and international classification of diseases, tenth edition (ICD-10). Addiction. 2006;101(Suppl 1):59-75.

25. Loupy A, Haas M, Solez K, Racusen L, Glotz D, Seron D, et al. The Banff 2015 kidney meeting report: current challenges in rejection classification and prospects for adopting molecular pathology. Am J Transplant. 2017;17(1):28-41.

26. Sharif A, Hecking M, de Vries AP, Porrini E, Hornum M, Rasoul-Rockenschaub $\mathrm{S}$, et al. Proceedings from an international consensus meeting on posttransplantation diabetes mellitus: recommendations and future directions. Am J Transplant. 2014;14(9):1992-2000.

27. Levy JC, Matthews DR, Hermans MP. Correct homeostasis model assessment (HOMA) evaluation uses the computer program. Diabetes Care. 1998;21(12): 2191-2.

28. Gupta S, Wallace MJ, Cardella JF, Kundu S, Miller DL, Rose SC, et al. Quality improvement guidelines for percutaneous needle biopsy. J Vasc Interv Radiol. 2010;21(7):969-75.

29. Batts KP, Ludwig J. Chronic hepatitis. An update on terminology and reporting. Am J Surg Pathol. 1995;19(12):1409-17.

30. Scheuer PJ. Classification of chronic viral hepatitis: a need for reassessment. J Hepatol. 1991;13(3):372-4. 
31. Wai CT, Greenson JK, Fontana RJ, Kalbfleisch JD, Marrero JA, Conjeevaram $\mathrm{HS}$, et al. A simple noninvasive index can predict both significant fibrosis and cirrhosis in patients with chronic hepatitis C. Hepatology. 2003;38(2): 518-26.

32. Andres-Otero MJ, De-Blas-Giral I, Puente-Lanzarote JJ, Serrano-Aullo T, Morandeira MJ, Lorente S, et al. Multiple approaches to assess fourteen non-invasive serum indexes for the diagnosis of liver fibrosis in chronic hepatitis C patients. Clin Biochem. 2016;49(7-8):560-5.

33. Sterling RK, Lissen E, Clumeck N, Sola R, Correa MC, Montaner J, et al. Development of a simple noninvasive index to predict significant fibrosis in patients with HIV/HCV coinfection. Hepatology. 2006;43(6):1317-25.

34. Bourliere M, Gordon SC, Flamm SL, Cooper CL, Ramji A, Tong M, et al. Sofosbuvir, Velpatasvir, and Voxilaprevir for previously treated HCV infection. N Engl J Med. 2017;376(22):2134-46.

35. Hirotsu Y, Kanda T, Matsumura H, Moriyama M, Yokosuka O, Omata M. HCV NS5A resistance-associated variants in a group of real-world Japanese patients chronically infected with HCV genotype 1b. Hepatol Int. 2015;9(3): 424-30

36. Lubetzky M, Chun S, Joelson A, Coco M, Kamal L, Ajaimy M, et al. Safety and efficacy of treatment of hepatitis $C$ in kidney transplant recipients with directly acting antiviral agents. Transplantation. 2017;101(7):1704-10.

37. Eisenberger U, Guberina H, Willuweit K, Bienholz A, Kribben A, Gerken G, et al. Successful treatment of Chronic hepatitis $C$ virus infection with Sofosbuvir and Ledipasvir in renal transplant recipients. Transplantation. 2017;101(5):980-6.

38. Siederdissen CHZ, Maasoumy B, Marra F, Deterding K, Port K, Manns MP, et al. Drug-drug interactions with novel all Oral interferon-free antiviral agents in a large real-world cohort. Clin Infect Dis. 2016;62(5):561-7.

39. Fujita N, Sugimoto R, Takeo M, Urawa N, Mifuji R, Tanaka H, et al. Hepcidin expression in the liver: relatively low level in patients with chronic hepatitis C. Mol Med. 2007;13(1-2):97-104.

40. Arcaini L, Vallisa D, Rattotti S, Ferretti W, Ferreri AJ, Bernuzzi P, et al. Antiviral treatment in patients with indolent B-cell lymphomas associated with HCV infection: a study of the Fondazione Italiana Linfomi. Ann Oncol. 2014;25(7): 1404-10.

41. Visentini M, Fiorilli M, Casato M. From the pathogenesis to the cure of indolent B-cell lymphoproliferative disorders associated with hepatitis $C$ virus infection: which role for direct-acting antivirals? Expert Rev Hematol. 2017;10(8):719-27.

42. Kralj D, Virovic Jukic L, Stojsavljevic S, Duvnjak M, Smolic M, Curcic IB. Hepatitis C virus, insulin resistance, and steatosis. J Clin Transl Hepatol. 2016; 4(1):66-75.

43. Kawaguchi $T$, Ide T, Taniguchi E, Hirano E, Itou M, Sumie S, et al. Clearance of HCV improves insulin resistance, beta-cell function, and hepatic expression of insulin receptor substrate 1 and 2. Am J Gastroenterol. 2007; 102(3):570-6.

44. Aytaman A, McFarlane SI. Uncovering glucose abnormalities in people with hepatitis $C$ infection: should oral glucose tolerance test become a standard of care? Am J Gastroenterol. 2008;103(8):1941-3.

45. Goldberg DS, Abt PL, Reese PP, Investigators TT. Transplanting HCV-infected kidneys into uninfected recipients. N Engl J Med. 2017;377(11):1105.

Ready to submit your research? Choose BMC and benefit from:

- fast, convenient online submission

- thorough peer review by experienced researchers in your field

- rapid publication on acceptance

- support for research data, including large and complex data types

- gold Open Access which fosters wider collaboration and increased citations

- maximum visibility for your research: over $100 \mathrm{M}$ website views per year

At BMC, research is always in progress.

Learn more biomedcentral.com/submissions 